\title{
Aproveitamento de nitrogênio pelo milho, em razão da adubação verde, nitrogenada e fosfatada
}

\author{
Edson Cabral da Silva(1), Takashi Muraoka ${ }^{(1)}$, Felipe Carlos Alvarez Villanueva $^{(1)}$ \\ e Freddy Sinencio Contreras Espinal(2)
}

(1)Universidade de São Paulo, Centro de Energia Nuclear na Agricultura, Avenida Centenário, oo 303, CEP 13416-000 Piracicaba, SP. E-mail: ecsilva@cena.usp.br, muraoka@cena.usp.br, falvarez@cena.usp.br (2)Instituto Dominicano de Investigaciones Agropecuarias y Forestales, Calle Rafael A. Sánchez, no 89, Ensanche Evaristo Morales, Santo Domingo, República Dominicana. E-mail: fcontreras@idiaf.org.do

Resumo - O objetivo deste trabalho foi avaliar o aproveitamento, pelo milho (Zea mays L.), do nitrogênio (N) proveniente da ureia, de restos culturais da crotalária (Crotalaria juncea) e do milheto (Pennisetum glaucum), e do solo, em função da adubação nitrogenada e fosfatada. $O$ experimento foi conduzido em casa de vegetação, em vasos com $5 \mathrm{~kg}$ de solo (Latossolo Vermelho distroférrico). Utilizou-se o delineamento inteiramente ao acaso, com 32 tratamentos e 4 repetições, dispostos em esquema fatorial $4 \times 4 \times 2$. Os tratamentos consistiram da combinação de quatro doses de $\mathrm{N}$, na forma de ureia - $0,0,75,1,50$ e $2,25 \mathrm{~g}$ por vaso (com ou sem marcação com ${ }^{15} \mathrm{~N}$ ); quatro doses de $\mathrm{P}$, na forma de superfosfato triplo - 0, 0,175, 0,350 e 0,700 g por vaso; e dois tipos de adubo verde, com ou sem marcação com ${ }^{15} \mathrm{~N}$ - crotalária e milheto, com adição de matéria seca equivalente a $1 \mathrm{~g}$ de $\mathrm{N}$ por vaso. Foram avaliados a produtividade de matéria seca, a quantidade de $\mathrm{N}$ acumulado e o aproveitamento do $\mathrm{N}$ pelo milho. $\mathrm{O}$ fertilizante mineral forneceu a maior parte do $\mathrm{N}$ acumulado nas plantas de milho, seguido pelo $\mathrm{N}$ do solo e de adubos verdes. $\mathrm{O}$ aproveitamento do $\mathrm{N}$ proveniente da crotalária, pelo milho, foi maior que o do $\mathrm{N}$ do milheto. A aplicação de fósforo aumentou a assimilação do $\mathrm{N}$ proveniente da ureia e de adubos verdes.

Termos de indexação: Crotalaria juncea, Pennisetum glaucum, Zea mays, diluição isotópica, mineralização de nitrogênio, ureia.

\section{Nitrogen utilization by corn as affected by green manures and nitrogen and phosphorus fertilizers}

\begin{abstract}
The objectives of this work were to evaluate corn (Zea mays) nitrogen $(\mathrm{N})$ utilization from the green manure crops sunnhemp (Crotalariajuncea) and millet (Pennisetum glaucum L.) and from urea, and to calculate the contribution of soil $\mathrm{N}$ to the mineral nutrition of corn, as affected by nitrogen and phosphorus mineral fertilizers. The experiment was conducted in a greenhouse, in pots with $5 \mathrm{~kg}$ of soil (Rhodic Hapludox). The experimental design was completely randomized, with 32 treatments and four replicates, in a $4 \times 4 \times 2$ factorial array. The treatments were combinations of four $\mathrm{N}$ rates as urea: $0,0.75,1.50$ and $2.25 \mathrm{~g} \mathrm{~N}$ per pot (labeled or not with ${ }^{15} \mathrm{~N}$ ); four P rates as triple superphosphate: $0,0.175,0.350$ and $0.700 \mathrm{~g} \mathrm{P}$ per pot; and sunnhemp and millet labeled or not with ${ }^{15} \mathrm{~N}$. Green manure dry matter provided $1 \mathrm{~g} \mathrm{~N}$ per pot. Corn plants were evaluated for dry mass yield, accumulated $\mathrm{N}$, and $\mathrm{N}$ utilization from green manures, urea, and the soil. The mineral fertilizer supplied the largest amount of $\mathrm{N}$ to the corn plants, followed by $\mathrm{N}$ from soil and from green manures. The $\mathrm{N}$ utilization from sunnhemp by corn plants was greater than the $\mathrm{N}$ utilization from millet. The phosphorus application increased the assimilation of $\mathrm{N}$ from urea and from green manures.
\end{abstract}

Index terms: Crotalaria juncea, Pennisetum glaucum, Zea mays, isotopic dilution, nitrogen mineralization, urea.

\section{Introdução}

O milho é o principal cereal produzido no Brasil e é cultivado em cerca de 14 milhões de hectares. Sua produtividade média é de 3,9 $\mathrm{t} \mathrm{ha}^{-1}$ de grãos (Conab, 2008). As doses baixas e o manejo incorreto do nitrogênio $(\mathrm{N})$ são fatores responsáveis por baixas produtividades nessa cultura (Amado et al., 2002). Enquanto no Brasil a quantidade utilizada de $\mathrm{N}$ no milho é, em média, de $60 \mathrm{~kg} \mathrm{ha}^{-1}$, nos EUA é de $150 \mathrm{~kg} \mathrm{ha}^{-1}$ e na China, de $130 \mathrm{~kg} \mathrm{ha}^{-1}$. A aplicação de fósforo (P) no milho também é baixa, no Brasil, com média de $35 \mathrm{~kg} \mathrm{ha}^{-1}$ de $\mathrm{P}_{2} \mathrm{O}_{5}$ (International Fertilizer Industry Association, 2008). 
$\mathrm{O} \mathrm{N}$ e o $\mathrm{P}$ são os nutrientes exigidos em maiores quantidades pelo milho e os que mais oneram o custo de produção, além de que, quando manejados inadequadamente, podem causar poluição dos recursos hídricos (Baird, 2002). A obtenção de altas produtividades de milho é diretamente dependente de elevadas doses de N (Amado et al., 2002; Sousa \& Lobato, 2004). Todavia, respostas aquém das expectativas, mesmo com altas doses de $\mathrm{N}$, podem ocorrer em razão da deficiência de $\mathrm{P}$ ou de outros nutrientes (Marschner, 1995). A deficiência de $\mathrm{P}$ pode induzir a de $\mathrm{N}$, principalmente pela redução nas taxas de absorção de nitrato (Lee et al., 1992; Alves et al., 1998), e a separação espacial dos nutrientes pode causar menor acúmulo de ambos na parte aérea do milho. Para Büll (1993), é marcante a influência do $\mathrm{N}$ na maior absorção de P pelo milho.

Alternativamente à adubação mineral, a adubação verde, principalmente com leguminosas, constitui-se numa importante maneira de adicionar $\mathrm{N}$ e reciclar outros nutrientes para as plantas, em virtude da liberação lenta e em sincronia com as necessidades das plantas (Amado et al., 2002; Araújo et al., 2005; Torres et al., 2008). De modo geral, as plantas de adubos verdes ou de culturas de cobertura, usadas para formar palhada para o sistema de semeadura direta (SSD), desempenham papel fundamental na ciclagem de nutrientes, tanto daqueles adicionados por meio dos fertilizantes minerais e não aproveitados pelas culturas comerciais, quanto daqueles provenientes da mineralização da matéria orgânica do solo (MOS) (Torres et al., 2008).

Atualmente, as culturas de cobertura e a cultura antecessora constituem-se um dos critérios para a recomendação de N para o milho em SSD no Rio Grande do Sul e em Santa Catarina (Amado et al., 2002). Sousa \& Lobato (2004) recomendam, entre os critérios para determinação da dose de $\mathrm{N}$ a ser recomendada para o milho, que se utilize um fator específico para gramíneas ou leguminosas, para estimar a contribuição do $\mathrm{N}$ proveniente de resíduos das três últimas culturas de verão, além do teor MOS.

Estudos demonstraram que o aumento de $20 \%$ no aproveitamento do $\mathrm{N}$ dos fertilizantes minerais pelos cereais representaria, mundialmente, uma economia de mais de U\$ 4,7 bilhões por ano (Raun \& Johnson, 1999).

Comparativamente às fontes minerais, em que a recuperação do $\mathrm{N}$ pelos cereais está em torno de 50\% (Raun \& Johnson, 1999; Lara Cabezas et al., 2004; Duete et al., 2008), a recuperação do $\mathrm{N}$ de adubos verdes tem sido baixa pela primeira cultura em sucessão, raramente superior a 20\% (Scivittaro et al., 2000; Araújo et al., 2005; Silva et al., 2006c). Isto que indica a permanência de grande parte do $\mathrm{N}$ no solo e pode proporcionar efeito residual nos cultivos subsequentes e aumentar o estoque de $\mathrm{N}$ orgânico do solo (Amado et al., 2002; Silva et al., 2006b). Em razão disto, postula-se que a combinação de fontes orgânicas de $\mathrm{N}$, na forma de adubos verdes, com fontes minerais seja uma alternativa de manejo viável, por reunir efeitos imediatos e de longo prazo (Scivittaro et al., 2000; Amado et al., 2002; Muraoka et al., 2002; Araújo et al., 2005). Assim, são necessários estudos que avaliem a recuperação do $\mathrm{N}$ de adubos verdes e o de fontes minerais, bem como a contribuição do $\mathrm{N}$ do solo para as culturas comerciais.

O objetivo deste trabalho foi avaliar o aproveitamento, pelo milho (Zea mays L.), do nitrogênio proveniente da ureia, de restos culturais da crotalária (Crotalaria juncea) e do milheto (Pennisetum glaucum), e do solo, em função da adubação nitrogenada e fosfatada.

\section{Material e Métodos}

O experimento foi conduzido em casa de vegetação, no Centro de Energia Nuclear na Agricultura, em Piracicaba, SP. Os ensaios foram realizados em vasos de plásticos com $5 \mathrm{~kg}$ de terra fina seca ao ar, coletada na camada de 0,0-0,2 m de um Latossolo Vermelho distroférrico, típico, A moderado, textura argilosa (440 $\mathrm{g} \mathrm{kg}^{-1}$ de argila), fase cerrado tropical subcaducifólio (Embrapa, 1999), com histórico de 26 anos de cultivo com culturas anuais (arroz, feijão, milho e soja).

As amostras de solo foram analisadas conforme Raij et al. (2001) e tiveram os seguintes resultados: $\mathrm{pH}\left(\mathrm{CaCl}_{2}\right) 4,8 ; \mathrm{N}$ total, $1 \mathrm{~g} \mathrm{~kg}^{-1}$; matéria orgânica, $12,7 \mathrm{~g} \mathrm{dm}^{-3} ; \mathrm{P}$ (resina), $11,7 \mathrm{mg} \mathrm{dm}^{-3} ; \mathrm{Ca}, 20 \mathrm{mmol}_{\mathrm{c}} \mathrm{dm}^{-3}$; $\mathrm{Mg}, 10,6 \mathrm{mmol}_{\mathrm{c}} \mathrm{dm}^{-3} ; \mathrm{K}, 2 \mathrm{mmol}_{\mathrm{c}} \mathrm{dm}^{-3} ; \mathrm{H}+\mathrm{Al}$, $26,1 \mathrm{mmol}_{\mathrm{c}} \mathrm{dm}^{-3} ; \mathrm{S}, 7,5 \mathrm{mg} \mathrm{dm}^{-3}$; SB, 32,6 $\mathrm{mmol}_{\mathrm{c}} \mathrm{dm}^{-3}$; CTC, $58,7 \mathrm{mmol}_{\mathrm{c}} \mathrm{dm}^{-3}$ e saturação por bases de $55 \%$.

$\mathrm{O}$ experimento compreendeu duas fases. Na primeira, produziram-se crotalária e milheto, com e sem marcação isotópica com ${ }^{15} \mathrm{~N}$. Na segunda, cultivou-se milho, combinando-se adubação verde sem marcação isotópica com aplicação de ureia marcada com ${ }^{15} \mathrm{~N}$ e adubação verde marcada isotopicamente combinada com ureia não marcada. Isto com a finalidade de distinguir a origem do $\mathrm{N}$ das distintas fontes.

A produção de crotalária e de milheto (variedade ADR 500) marcados com ${ }^{15} \mathrm{~N}$ foi realizada em vasos 
com $5 \mathrm{~kg}$ de solo, semeando-se 12 sementes e mantendose 6 plantas por vaso, após o desbaste realizado cinco dias após a emergência (DAE). A marcação isotópica foi realizada aplicando-se ao solo de cada vaso uma solução com $1 \mathrm{~g}$ de ureia marcada com ${ }^{15} \mathrm{~N}\left({ }^{15} \mathrm{~N}\right.$-ureia), enriquecida com $10 \%$ de átomos de ${ }^{15} \mathrm{~N}$ em excesso, e aplicando-se semanalmente $1 / 3$ dessa dose, a partir dos 10 DAE. Simultaneamente, foram cultivados milheto e crotalária sem marcação isotópica, com aplicação da mesma quantidade de ureia comercial (não enriquecida), para a determinação da abundância natural de ${ }^{15} \mathrm{~N}$ no adubo verde e para uso na combinação de tratamentos com ureia marcada. As plantas foram regadas diariamente com água destilada.

A colheita da crotalária e do milheto foi realizada aos $70 \mathrm{DAE}$, e o material, separado em raízes e parte aérea, foi lavado e seco a $60^{\circ} \mathrm{C}$ em estufa por 72 horas. Após a secagem, o material foi fragmentado em pedaços de aproximadamente $0,02 \mathrm{~m}$ e misturado ao solo, dez dias antes da semeadura do milho, numa proporção de $4: 1$ de parte aérea e raiz, conforme os rendimentos obtidos das respectivas partes.

No cultivo do milho, utilizaram-se vasos com $5 \mathrm{~kg}$ de solo, dispostos num delineamento experimental inteiramente ao acaso, com 32 tratamentos e quatro repetições, dispostos em esquema fatorial $4 \times 4 \times 2$. Os tratamentos compreenderam a combinação de quatro doses de N, na forma de ureia: 0, 0,75, 1,50 e 2,25 g de N por vaso (com ou sem marcação com ${ }^{15} \mathrm{~N}$ ), quatro doses de P, na forma de superfosfato triplo: $0,0,175,0,350 \mathrm{e} 0,700 \mathrm{~g}$ de $\mathrm{P}$ por vaso, e os adubos verdes crotalária (Crotalaria juncea L.) e milheto (Pennisetum glaucum L.), aplicandose a quantidade de matéria seca para fornecer $1 \mathrm{~g}$ de $\mathrm{N}$ por vaso. Os tratamentos foram duplicados para estabelecer as combinações antes descritas, ou seja: ${ }^{15} \mathrm{~N}$-ureia com adubo verde não marcado e vice-versa.

A semeadura do milho foi realizada adicionando-se três sementes por vaso do híbrido simples Pioneer 30F80, deixando-se uma planta após desbaste, realizado aos 5 DAE. Exceto para o tratamento testemunha (sem N mineral), foi aplicada a dose de $0,375 \mathrm{~g}$ de $\mathrm{N}$ por vaso na semeadura. $\mathrm{O}$ restante das doses de $\mathrm{N}$ foi aplicado em cobertura, quando as plantas apresentavam quatro folhas totalmente expandidas (linha de união lâmina-bainha facilmente visível). A ureia utilizada, inclusive a aplicada na semeadura, apresentava enriquecimento de 2,0, 1,5 e $1,0 \%$ de átomos de ${ }^{15} \mathrm{~N}$ em excesso, respectivamente para os tratamentos: $0,75,1,50$ e $2,25 \mathrm{~g}$ de $\mathrm{N}$ por vaso, para não onerar o custo do experimento. Esse procedimento é passível de ser realizado, já que na metodologia isotópica os cálculos, em cada tratamento, são realizados em relação ao respectivo enriquecimento utilizado, o que não influencia os resultados de aproveitamento do $\mathrm{N}$ (IAEA, 2001).

Durante o experimento, as plantas foram regadas, diariamente, com água deionizada com condutividade elétrica de $0,6 \mu \mathrm{S} \mathrm{cm}^{-1}$, a fim de manter a umidade do solo em torno de $60 \%$ da capacidade de campo.

A colheita do milho foi realizada aos $120 \mathrm{DAE}$, com o corte das plantas rente à superfície do solo, sendo o material (palha mais grãos) seco em estufa a $65^{\circ} \mathrm{C}$, por 72 horas, para obtenção da massa de matéria seca total. Em seguida, o material foi misturado, moído em moinho tipo Wiley com peneira de 40 mesh $(0,42 \mathrm{~mm})$, homogeneizado e, desse material, foram retiradas amostras para determinação do $\mathrm{N}$ total e da concentração isotópica.

A relação $\mathrm{C} / \mathrm{N}$ dos resíduos vegetais dos adubos verdes foi determinada pela metodologia de combustão via seca da amostra, a $1.400^{\circ} \mathrm{C}$, com uso do aparelho LECO C/N (Nelson \& Sommers, 1982). O teor de N total e a abundância em átomos de ${ }^{15} \mathrm{~N}$, tanto nos adubos verdes quanto no milho, foram determinados em espectrômetro de massa, com analisador automático de $\mathrm{N}$, conforme método descrito em Barrie \& Prosser (1996). A sequência de cálculos para a determinação da recuperação do $\mathrm{N}$ do fertilizante foi realizada conforme Lara Cabezas et al. (2004) e Silva et al. (2006c).

Os dados foram submetidos à análise de variância e, quando detectados efeitos significativos pelo teste $\mathrm{F}$, a 5\% de probabilidade, foram ajustadas equações de regressão. Testou-se a significância dos componentes linear e quadrático da regressão, tendo-se escolhido o modelo com maior grau de significância. $\mathrm{O}$ teor de $\mathrm{N}$ total e a relação $\mathrm{C} / \mathrm{N}$ dos adubos verdes foram comparados pelo teste Tukey, a 5\% de probabilidade. As análises estatísticas foram realizadas utilizando-se o SAS 8.02 (SAS Institute, 2001).

\section{Resultados e Discussão}

A parte aérea da crotalária e do milheto apresentaram maior teor de $\mathrm{N}$ do que o sistema radicular (Tabela 1), semelhantemente ao observado, em casa de vegetação, por Scivittaro et al. (2000) e Ambrosano et al. (2003). Já a concentração de ${ }^{15} \mathrm{~N}$ (percentagem de átomos) não foi muito discrepante entre as diferentes partes da planta, provavelmente em razão da grande mobilidade do $\mathrm{N}$ dentro da planta (Silva et al., 2008). O enriquecimento 
de ${ }^{15} \mathrm{~N}$ obtido (acima de 3,2\%) é suficiente para o estudo da dinâmica e do aproveitamento do N no sistema soloplanta já que, segundo Ambrosano et al. (2003), valores acima de $2 \%$ em átomos de ${ }^{15} \mathrm{~N}$ são requeridos para se obter resultados satisfatórios. A crotalária apresentou maior concentração de $\mathrm{N}$ na matéria seca, e sua relação $\mathrm{C} / \mathrm{N}$ foi inferior à do milheto, o que era esperado por se tratar de uma leguminosa (Amado et al., 2002).

A análise de variância mostrou efeito significativo $(p<0,01)$ da interação entre nitrogênio mineral e adubo verde sobre a produtividade de grãos, teor e conteúdo de $\mathrm{N}$ e sobre todas as variáveis relacionadas ao $\mathrm{N}$ na planta proveniente das diversas fontes.

Não se observou interação significativa entre o P e os demais fatores. No entanto, houve efeito significativo do $\mathrm{P}$ sobre a quantidade de $\mathrm{N}$ na planta proveniente do fertilizante e dos adubos verdes e sobre o aproveitamento do $\mathrm{N}$ do fertilizante e dos adubos verdes. Os coeficientes de variação, de maneira geral, situaram-se abaixo de $10 \%$.

A produtividade de matéria seca do milho cultivado na presença de resíduos de crotalária ou milheto aumentou de forma quadrática em função das doses de $\mathrm{N}$ aplicadas (Figura 1 A). Independentemente da dose de N, os maiores valores de matéria seca foram observados no milho cultivado na presença de resíduos de crotalária, em que o ponto de máxima (122 g por planta) foi alcançado com a dose de $1,89 \mathrm{~g}$ de $\mathrm{N}$ por vaso. Para o milho cultivado na presença de milheto, a máxima produtividade $(113 \mathrm{~g}$ por planta) foi atingida com a dose de $1,98 \mathrm{~g}$ de $\mathrm{N}$ por vaso. A maior resposta em produtividade de matéria seca do milho cultivado na presença de resíduos de crotalária ocorreu em razão do maior e mais regular fornecimento de $\mathrm{N}$ pela leguminosa. Sua menor $\mathrm{C} / \mathrm{N}$ (Tabela 1) favoreceu a mineralização de seus resíduos. Estudos têm demonstrado que a fase da planta em que o $\mathrm{N}$ é absorvido influencia diretamente o acúmulo de matéria seca pelo milho (Duete et al., 2008). Assim, a taxa de mineralização do $\mathrm{N}$ de resíduos vegetais pode ter efeito na produtividade dessa cultura.

Ressalta-se que a produtividade de matéria seca por planta (Figura $1 \mathrm{~A}$ ) foi inferior à que normalmente é obtida em condições de campo. Esse fato, possivelmente, está relacionado às condições de vaso, que desfavorecem o acúmulo de matéria seca, sobretudo pelo menor volume de solo explorado pelas raízes.

Os teores de $\mathrm{N}$ na matéria seca foram proporcionais à dose de fertilizante mineral nitrogenado aplicada (Figura 1 B). Apenas os tratamentos que receberam a menor dose de $\mathrm{N}$, na presença de milheto, e os tratamento com omissão de $\mathrm{N}$, com ambas as espécies, tiveram teores de $\mathrm{N}$ abaixo dos descritos como adequados na planta inteira de milho, de cerca de $10 \mathrm{~g} \mathrm{~kg}^{-1}$ de matéria seca (Grove et al., 1980; Coelho et al., 1991). Nos tratamentos com resíduos de crotalária, os maiores teores de $\mathrm{N}$ implicaram maior quantidade de $\mathrm{N}$ acumulado (Figura $1 \mathrm{C}$ ), que aumentou de forma quadrática em relação às doses de $\mathrm{N}$. Nos tratamentos com milheto, a quantidade de $\mathrm{N}$ acumulado aumentou de forma linear em relação às doses de $\mathrm{N}$, evidência de que a maior oferta de $\mathrm{N}$ mineral reduziu a imobilização de $\mathrm{N}$ pela microbiota do solo. Pesquisas demonstram que resíduos vegetais com relação $\mathrm{C} / \mathrm{N}$ acima de 25/1 favorecem o processo de imobilização temporária do $\mathrm{N}$ mineral da solução do solo pelos microrganismos. Já resíduos com relação $\mathrm{C} / \mathrm{N}$ inferior a $25 / 1$ favorecem a mineralização e a rápida liberação do $\mathrm{N}$ e demais nutrientes presentes em sua biomassa (Amado et al., 2002; Muraoka et al., 2002; Silva et al., 2008). Entretanto, esse processo está também relacionado às condições edafoclimáticas, sobretudo temperatura, umidade e textura do solo (Lara Cabezas et al., 2004; Sousa \& Lobato, 2004).

A percentagem do $\mathrm{N}$ na planta de milho proveniente do milheto e da crotalária (\%NPPAV) decresceu, enquanto a quantidade de $\mathrm{N}$ na parte aérea proveniente dessas fontes (QNPPAV) aumentou com o aumento da dose de $\mathrm{N}$ (Figura $1 \mathrm{D}$ e E).

$\mathrm{O}$ aproveitamento do $\mathrm{N}$ mineralizado dos adubos verdes (Figura $1 \mathrm{~F}$ ) seguiu a mesma tendência da QNPPAV, em decorrência, possivelmente, de ter sido aplicada a mesma quantidade de $\mathrm{N}$ na forma de resíduos em todos os vasos (Scivittaro et al., 2000; Araújo et al., 2005; Silva et al., 2008).

Verifica-se, na Figura $1 \mathrm{D}$, que a \%NPPAV foi maior nos tratamentos não fertilizados com $\mathrm{N}$ mineral. Esse resultado deveu-se ao fato de que, nesses tratamentos,

Tabela 1. Teor de nitrogênio total, concentração de ${ }^{15} \mathrm{~N}$ e relação $\mathrm{C} / \mathrm{N}$ dos resíduos vegetais de milheto e crotalária aplicados ao solo como fonte de nitrogênio para o milho ${ }^{(1)}$.

\begin{tabular}{lccc}
\hline Adubos verdes & $\begin{array}{c}\text { Nitrogênio total } \\
\left(\mathrm{g} \mathrm{kg}^{-1}\right)\end{array}$ & $\begin{array}{c}\text { Concentração de }{ }^{15} \mathrm{~N} \\
(\% \text { de átomos em excesso })\end{array}$ & Relação C/N \\
\hline Crotalária & $23,9 \mathrm{a}$ & Parte aérea & $18 / 1 \mathrm{~b}$ \\
Milheto & $17,5 \mathrm{~b}$ & 3,751 & $35 / 1 \mathrm{a}$ \\
\hline & & 3,501 & $22 / 1 \mathrm{~b}$ \\
Crotalária & $19,5 \mathrm{a}$ & Sistema radicular \\
Milheto & $11,9 \mathrm{~b}$ & 3,646 & $33 / 1 \mathrm{a}$ \\
\hline
\end{tabular}

${ }^{(1)}$ Médias seguidas de letras iguais, na coluna, não diferem entre si pelo teste de Tukey, a $5 \%$ de probabilidade. 

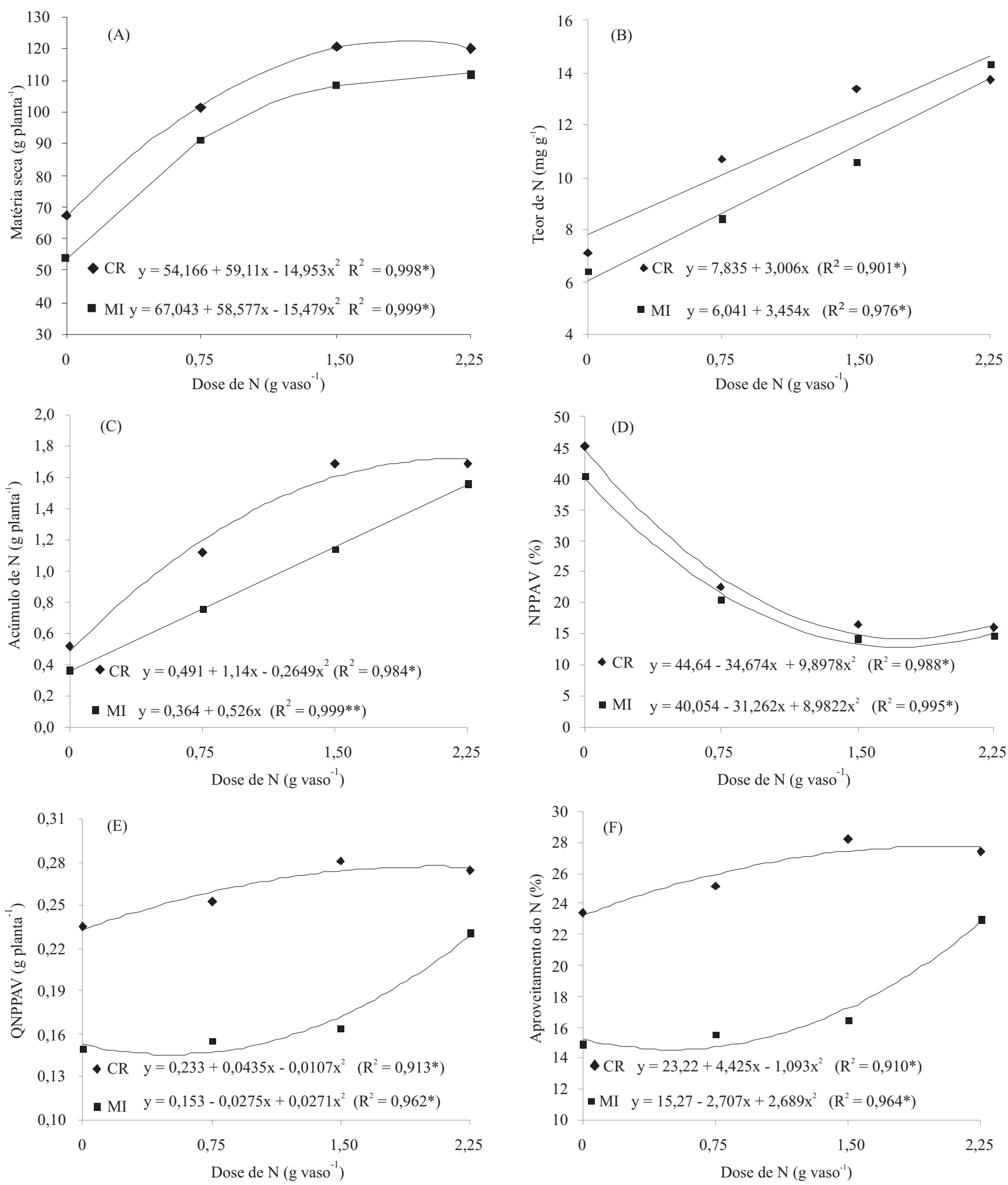

Figura 1. Produtividade de matéria seca (A), teor de nitrogênio total (B) e quantidade de nitrogênio acumulado na parte aérea do milho (C); porcentagem (NPPAV) (D), quantidade (QNPPAV) (E) e aproveitamento do nitrogênio (F) proveniente da crotalária (CR) e do milheto (MI) pela parte aérea do milho, em função de diferentes doses de nitrogênio. * e **Modelo significativo a 5 e $1 \%$ de probabilidade, respectivamente, pelo teste $\mathrm{F}$. 
as únicas fontes de $\mathrm{N}$ para a planta de milho foram o adubo verde e o solo. Comportamento contrário ocorreu com a QNPPAV (Figura 1 E). Resultados semelhantes foram observados por Scivittaro et al. (2000), ao estudar a absorção do N da mucuna-preta ou da ureia pelo milho, e também por Araújo et al. (2005), ao avaliar o aproveitamento do $\mathrm{N}$ da ureia e da crotalária pelo trigo.

Os valores médios de aproveitamento do $\mathrm{N}$ do milheto $(17,5 \%)$ e da crotalária $(26,1 \%)$ foram superiores aos observados por Silva et al. (2006c), em condições de campo: $8 \%$ para o $\mathrm{N}$ do milheto e $13 \%$ para o $\mathrm{N}$ da crotalária. Foram superiores também aos resultados obtidos por Silva et al. (2008), em condições de casa de vegetação: $20,3 \%$ para o $\mathrm{N}$ da crotalária e $5,6 \%$ para o $\mathrm{N}$ do milheto. Essa superioridade deveu-se, possivelmente, ao fato de que, nesses estudos, os resíduos não foram incorporados ao solo, ao contrário do que foi realizado no presente trabalho, e a incorporação favorece a decomposição/mineralização (Amado et al., 2002; Lara Cabezas et al., 2004; Silva et al., 2008). O maior aproveitamento do $\mathrm{N}$ mineralizado dos adubos verdes, neste trabalho, comparado aos normalmente obtidos em condições de campo, provavelmente foi em razão das menores perdas de $\mathrm{N}$, já que o sistema radicular pôde explorar todo o volume de solo do vaso, a exemplo do observado por Villas Bôas et al. (1999).

A percentagem (\%NPPF) e a quantidade (QNPPF) de $\mathrm{N}$ na planta de milho proveniente do fertilizante mineral (Figura $2 \mathrm{Ae} \mathrm{B}$ ) foram proporcionais à dose de $\mathrm{N}$ aplicada. Para milho cultivado na presença de resíduos de milheto, os dados ajustaram-se ao modelo linear, de acordo com o aumento nas doses de N. A mesma tendência foi observada na presença de crotalária. Comportamento semelhante foi observado por Scivittaro et al. (2000), para o $\mathrm{N}$ proveniente da ureia, em milho cultivado na presença de mucuna-preta.

$\mathrm{O}$ aproveitamento do $\mathrm{N}$ do fertilizante mineral decresceu com o aumento das doses de N (Figura $2 \mathrm{C}$ ), o que condiz com a literatura (Muraoka et al., 2002; Araújo et al., 2005; Silva et al., 2006a). No entanto, ressalta-se que o aproveitamento é relativo à dose de $\mathrm{N}$ aplicada $\mathrm{e}$, assim como nos resultados observados neste trabalho, a quantidade de $\mathrm{N}$ absorvida pelo milho normalmente aumenta com o aumento da dose de N aplicada (Silva et al., 2006a; Duete et al., 2008).

De maneira geral, a crotalária proporcionou maiores valores para \%NPPF, QNPPF e aproveitamento do N
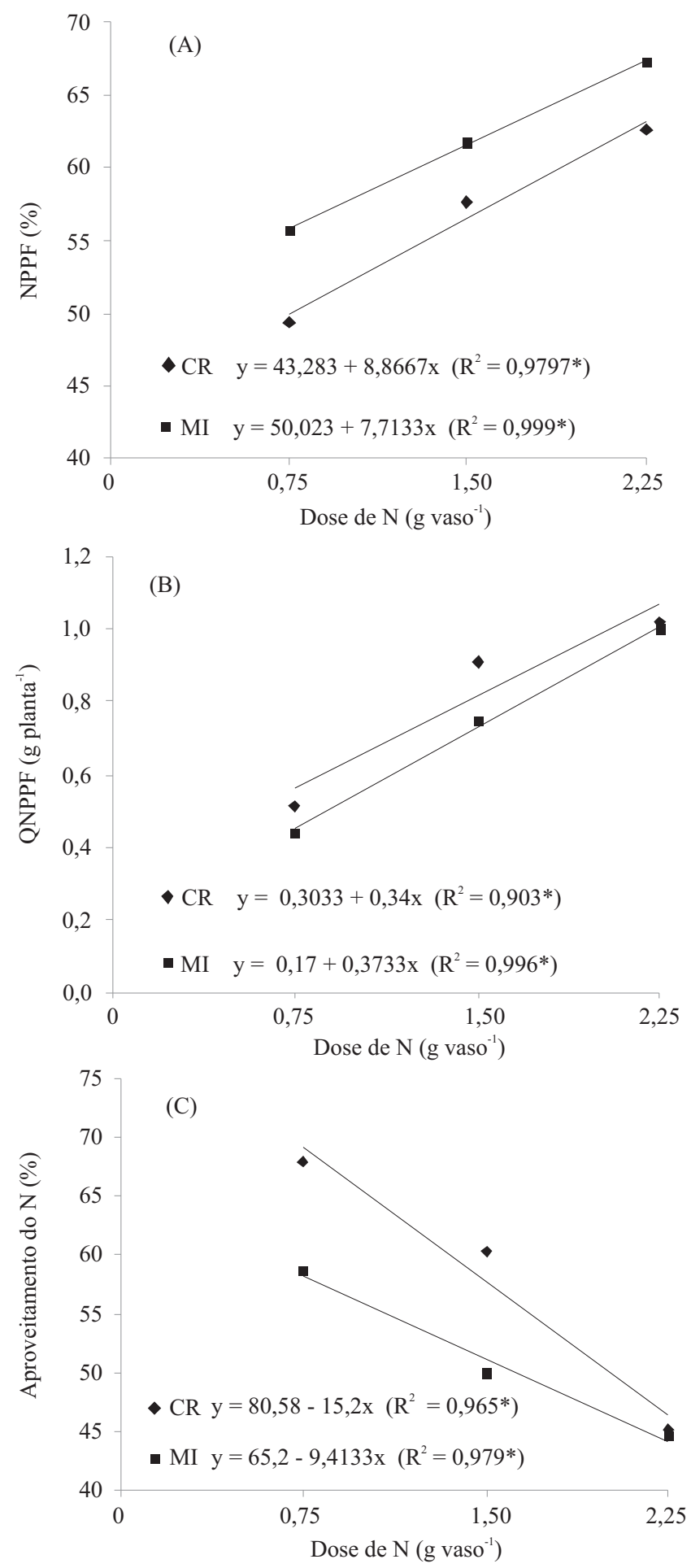

Figura 2. Percentagem (NPPF) (A), quantidade (QNPPF) (B) e aproveitamento (C) do nitrogênio proveniente do fertilizante mineral (ureia) pela parte aérea do milho, em função de diferentes doses de nitrogênio, cultivado na presença de resíduos de crotalária (CR) ou milheto (MI). *Modelo significativo a $5 \%$ de probabilidade, pelo teste $\mathrm{F}$. 
da ureia, comparada ao milheto (Figura $2 \mathrm{~A}, \mathrm{~B}$ e C). Isso indica que essa espécie proporcionou condições mais favoráveis à absorção do $\mathrm{N}$ da ureia pelo milho, a exemplo do observado por Araújo et al. (2005) e Silva et al. (2006c, 2008). Em estudos com o milho, em Latossolo Vermelho, utilizando-se métodos isotópicos com ${ }^{15} \mathrm{~N}$, foram encontradas diferentes eficiências de recuperação do $\mathrm{N}$ do fertilizante pelo milho: $50 \%$ (Grove et al., 1980); 57\% (Coelho et al., 1991); 43\% (Villas Bôas et al., 1999); 43\% (Scivittaro et al., 2000) 26 a 49\% (Figueiredo et al., 2005); 40 a 50\% (Silva et al., 2006a); 45\% (Gava et al., 2006) e 39\% (Duete et al., 2008). A variação no aproveitamento do $\mathrm{N}$ proveniente de fertilizantes minerais pelo milho é decorrente de diversos fatores, principalmente das
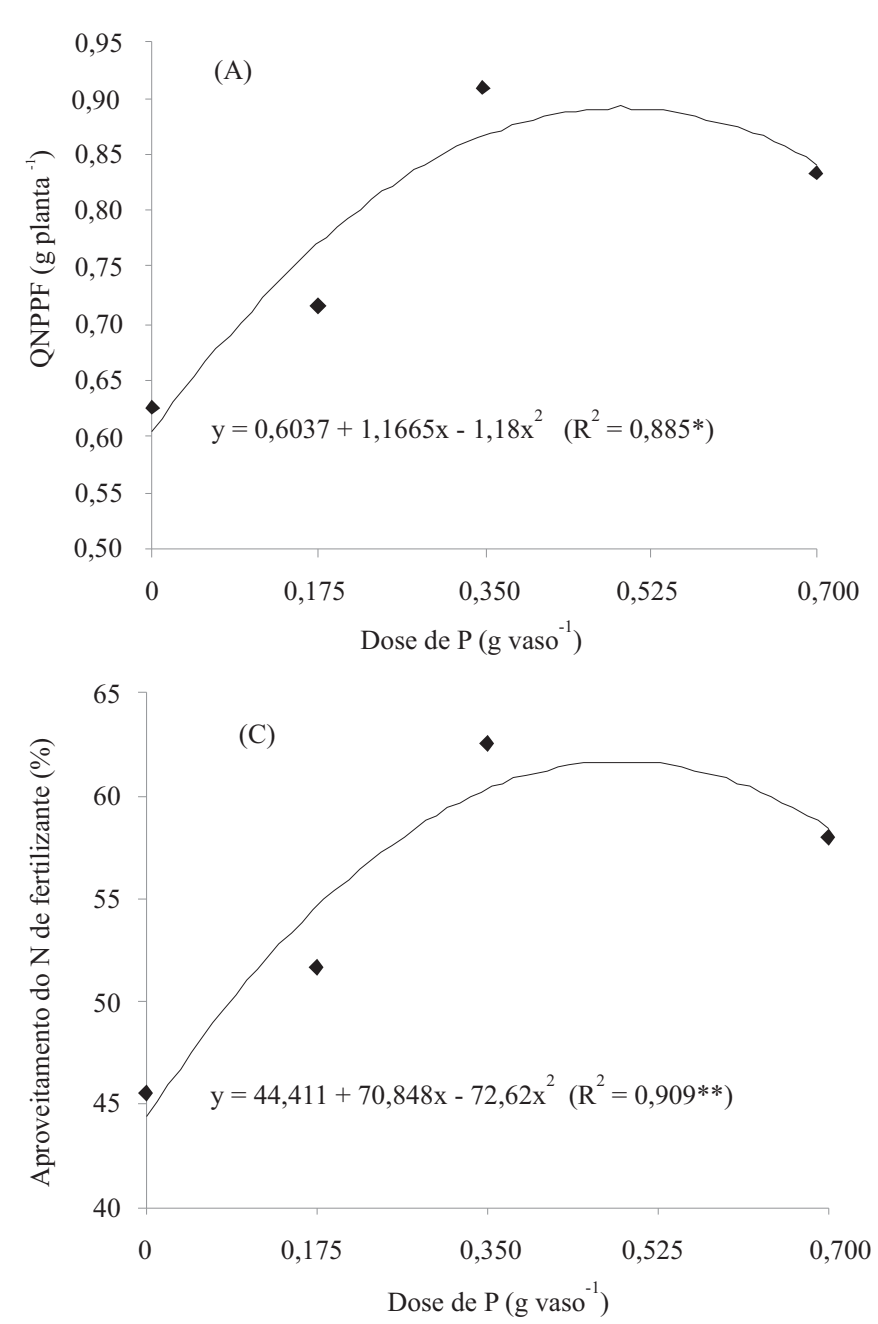

condições edafoclimáticas, do fertilizante utilizado, do manejo da adubação (dose, época e modo de aplicação) e do sistema de cultivo (semeadura direta ou preparo convencional) (Fernandes et al., 1999; Lara Cabezas et al., 2004; Duete et al., 2008). As perdas de N por lixiviação, volatilização, desnitrificação e erosão e a imobilização microbiana também têm influência no aproveitamento do $\mathrm{N}$ proveniente de fontes minerais (Lara Cabezas et al., 2004; Figueiredo et al., 2005).

A QNPPF (Figura $3 \mathrm{~A}$ ) e o aproveitamento do $\mathrm{N}$ da ureia (Figura $3 \mathrm{C}$ ) foram menores nos tratamentos sem fertilizante fosfatado. A absorção de $\mathrm{N}$ foi estimulada pela presença de $\mathrm{P}$, e foi mais intensa no tratamento com $0,350 \mathrm{~g}$ de $\mathrm{P}$ por vaso. Esse comportamento também ocorreu para a QNPPAV (Figura 3 B) e
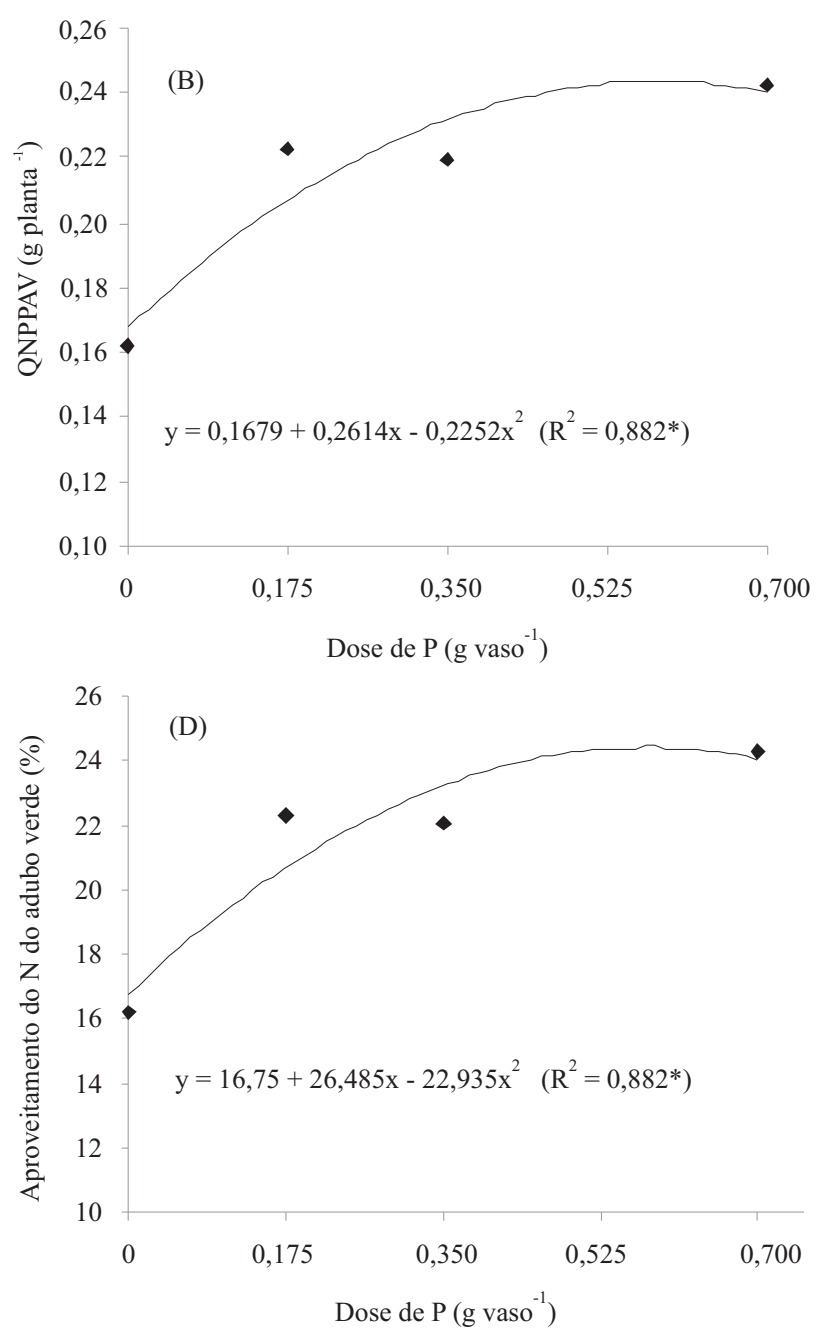

Figura 3. Quantidade de nitrogênio na planta (parte aérea) de milho proveniente do fertilizante mineral (QNPPF) (A) e dos adubos verdes (QNPPAV) crotalária e milheto (B) e aproveitamento pelo milho do $\mathrm{N}$ do fertilizante (C) e dos adubos verdes (D), em função de diferentes doses de fósforo. * e **Modelo significativo a 5 e $1 \%$ de probabilidade, respectivamente, pelo teste $\mathrm{F}$. 
aproveitamento do $\mathrm{N}$ dos adubos verdes (Figura $3 \mathrm{D}$ ). No entanto, a maior recuperação do $\mathrm{N}$ proveniente dos adubos verdes pelo milho foi obtida com a maior dose de P (0,700 g de P por vaso). Esses resultados demonstram a influência do $\mathrm{P}$ na absorção de $\mathrm{N}$, a exemplo do relatado por Marschner (1995). Diversos autores têm constatado redução na taxa de absorção de nitrato como consequência da deficiência de $\mathrm{P}$ (Lee et al., 1992; Alves et al., 1998). Alves et al. (1998) verificaram que a velocidade máxima de absorção (Vmax) de nitrato e de amônio pela planta foi menor quando o $\mathrm{N}$ e o $\mathrm{P}$ foram aplicados em vasos separados do que quando foram aplicados no mesmo vaso.

$\mathrm{A}$ aplicação de $\mathrm{P}$ aumentou a recuperação do $\mathrm{N}$ proveniente tanto do fertilizante mineral (Figura $3 \mathrm{~A}$ ) quanto dos adubos verdes (Figura $3 \mathrm{~B}$ ), apesar de a interação entre os fatores não ter sido significativa. Considerando-se os valores do aproveitamento do $\mathrm{N}$ em função da aplicação de P (Figura $3 \mathrm{C}$ e D), podese observar uma amplitude dos valores de cerca de $16 \%$, para o $\mathrm{N}$ da ureia, e de $8 \%$, para o $\mathrm{N}$ dos adubos verdes. Esse aumento no aproveitamento do $\mathrm{N}$ pode ser expressivo em termos econômicos e ambientais.

A contribuição do $\mathrm{N}$ do fertilizante mineral para o $\mathrm{N}$ acumulado no milho cultivado, na presença de resíduos de crotalária, foi proporcional à dose aplicada (Figura 4 A). Para o milho sobre resíduos de milheto (Figura 4 B), os tratamentos que receberam as duas maiores doses de $\mathrm{N}$ apresentaram valores semelhantes. Comparando-se os valores de NPPF com os de NPPAV, tanto na presença de crotalária quanto de milheto, verifica-se que o fertilizante contribuiu com mais do dobro do $\mathrm{N}$ absorvido pelo milho. Resultados semelhantes foram obtidos por Scivittaro et al. (2000) e Araújo et al. (2005). No entanto, em média, 42\% do $\mathrm{N}$ da ureia aplicada aos tratamentos com crotalária $\mathrm{e}$ $49 \%$ do $\mathrm{N}$ da ureia aplicada aos tratamentos com milheto não foram aproveitados pelo milho.

De maneira geral, a maior fração do $\mathrm{N}$ dos resíduos vegetais (Figura 4 A e B) não foi absorvida pelo milho, podendo-se supor que a maior parte do $\mathrm{N}$ remanescente dessas fontes e grande parte do $\mathrm{N}$ da ureia permaneceram no solo, principalmente sob formas orgânicas, a exemplo do relatado em outros estudos (Azam et al., 1985, 1995; Scivittaro et al., 2000; Amado et al., 2002; Silva et al., 2006c). Assim, o cultivo de adubos verdes pode favorecer outras culturas em rotação ou sucessão (Scivittaro et al., 2000; Araújo et al., 2005) e aumentar o estoque de $\mathrm{N}$ orgânico do solo.

$\mathrm{O}$ fertilizante mineral foi a principal fonte do $\mathrm{N}$ acumulado nas plantas de milho, seguido, em ordem decrescente, pelo solo e adubos verdes. Esse resultado diferiu do obtido por Azam et al. (1985), em solo com baixo teor de $\mathrm{N}$, onde a contribuição das três fontes foi equitativa. Por sua vez, Scivittaro et al. (2000) observaram que o solo foi a principal fonte de $\mathrm{N}$ para o milho.
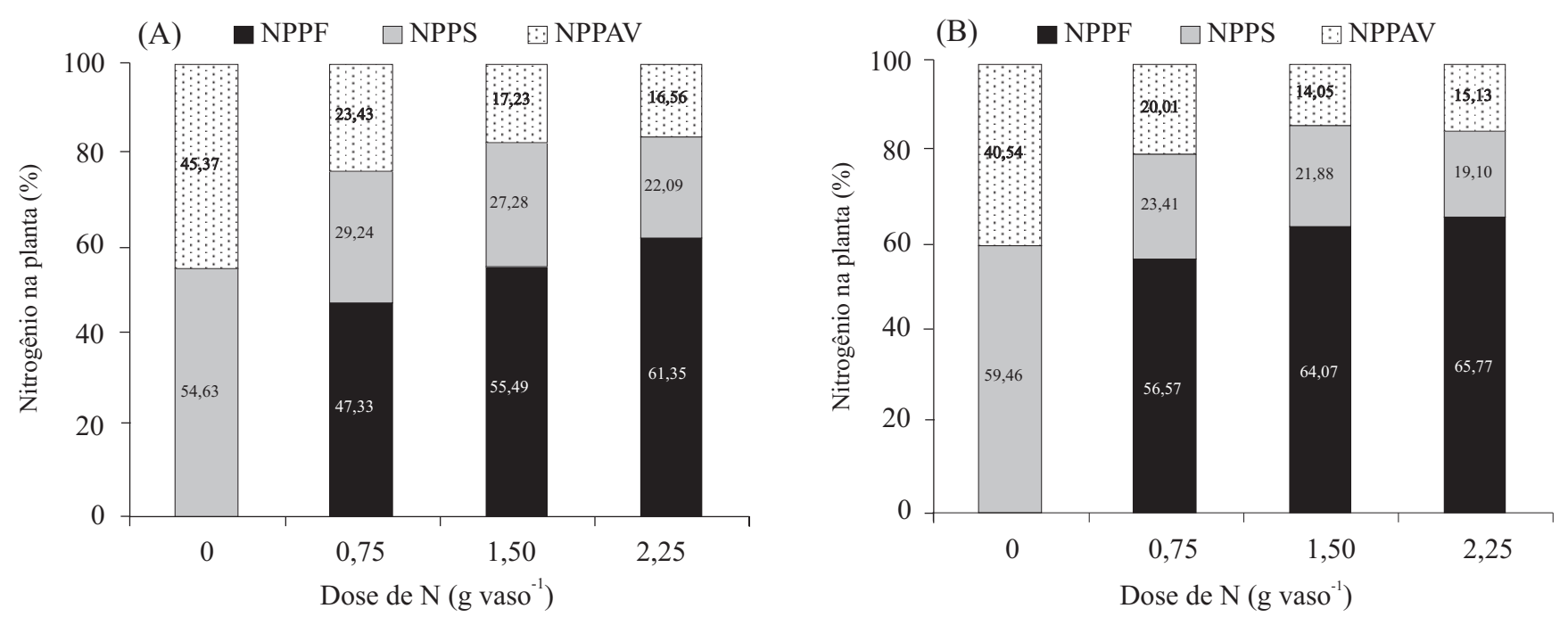

Figura 4. Contribuição relativa das fontes nitrogenadas utilizadas: fertilizante (ureia) (NPPF), solo (NPPS) e adubos verdes (NPPAV) crotalária (A) e milheto (B), para o nitrogênio acumulado na parte aérea do milho, em razão de diferentes doses aplicadas de nitrogênio mineral. 
O fertilizante mineral nitrogenado promoveu efeito sinérgico na absorção de $\mathrm{N}$ do solo. A quantidade de $\mathrm{N}$ proveniente do solo, nos tratamentos que receberam as doses $0,0,75,1,50$ e $2,25 \mathrm{~g}$ de $\mathrm{N}$ por vaso foi, respectivamente, de $0,283,0,315,0,445$ e $0,366 \mathrm{~g}$ por planta, para o milho cultivado na presença de resíduos de crotalária, e de $0,220,0,183,0,256$ e 0,292 g por planta, na presença de resíduos de milheto. O efeito positivo de fontes orgânicas e minerais de $\mathrm{N}$ sobre a absorção de N, conhecido como efeito "priming", é relatado com frequência na literatura (Jenkson et al., 1985; Scivittaro et al., 2000; Silva et al., 2006b). A constatação do efeito "priming" sugere que os benefícios atribuídos ao $\mathrm{N}$ de fertilizantes minerais ou de adubos verdes, adicionados ao solo, são superestimados, já que, em parte, o maior acúmulo de $\mathrm{N}$ está relacionado à maior absorção de $\mathrm{N}$ do solo (Scivittaro et al., 2000).

Com relação à utilização pelo milho do $\mathrm{N}$ proveniente de adubos verdes, da ureia e do N nativo do solo, ressalta-se que os valores obtidos neste trabalho desconsideraram o $\mathrm{N}$ contido no sistema radicular do milho, e representam, portanto, uma subestimativa do total recuperado. Possivelmente, esse fato assume maior relevância para o aproveitamento do $\mathrm{N}$ dos adubos verdes, uma vez que existem relatos de que grande parte do $\mathrm{N}$ de adubos verdes absorvido pelas plantas de milho fica retida nas raízes (Azam et al., 1995; Scivittaro et al., 2000). Isso ocorre pelo fato de o produto da degradação do $\mathrm{N}$ dessa fonte ser absorvido e metabolizado pelas raízes antes de ser mineralizado para $\mathrm{NO}_{3}^{-} . \mathrm{O} \mathrm{N}$ de fontes minerais é mais rapidamente absorvido e translocado para a parte aérea (Azam et al., 1985).

Em condições de campo, a principal fonte de $\mathrm{N}$ para o milho é o solo (Amado et al., 2002; Silva et al., 2006b), diferentemente do que foi observado neste trabalho em casa de vegetação (Figura $4 \mathrm{~A}$ e B), o que pode ser explicado pelo menor volume de solo explorado pelas raízes nestas condições.

\section{Conclusões}

1. O aumento da dose de nitrogênio aplicada ao solo proporciona aumento na quantidade de nitrogênio proveniente do fertilizante na parte aérea do milho e reduz a eficiência de aproveitamento desse nutriente.
2. O fertilizante mineral fornece a maior parte do nitrogênio acumulado nas plantas de milho, seguido pelo solo e pelos adubos verdes.

3. O aproveitamento pelo milho do nitrogênio da crotalária é maior do que o do milheto.

4. A aplicação de fósforo aumenta a assimilação de nitrogênio proveniente da ureia e de adubos verdes pelo milho.

\section{Agradecimentos}

À Fundação de Amparo à Pesquisa do Estado de São Paulo, pela concessão de bolsa e auxílio financeiro.

\section{Referências}

ALVES, V.M.C.; MAGALHÃES, J.V. de; NOVAIS, R.F. de; BAHIA FILHO, A.F. de C.; OLIVEIRA, C.A. de; FRANÇA, C.C. de M. Localização de fósforo e de nitrogênio afetando os parâmetros cinéticos de absorção de nitrogênio em milho. Revista Brasileira de Fisiologia Vegetal, v.10, p.197-201, 1998.

AMADO, T.J.C.; MILNICZUK, J.; AITA, C. Recomendação de adubação nitrogenada para o milho no RS e SC adaptada ao uso de culturas de cobertura do solo, sob sistema plantio direto. Revista Brasileira de Ciência do Solo, v.26, p.241-248, 2002.

AMBROSANO, E.J.; TRIVELIN, P.C.O.; CANTARELLA, H.; ROSSETTO, R.; MURAOKA, T.; BENDASSOLLI, J.A.; AMBROSANO, G.M.B.; TAMISO, L.G.; VIEIRA, F. de C.; PRADA NETO, I. Nitrogen-15 labeling of Crotalaria juncea green manure. Scientia Agricola, v.60, p.181-184, 2003.

ARAÚJO, A.S.F. de; TEIXEIRA, G.M.; CAMPOS, A.X. de; SILVA, F.C.; AMBROSANO, E.J.; TRIVELIN, P.C.O. Utilização de nitrogênio pelo trigo cultivado em solo fertilizado com adubo verde (Crotalaria juncea) e/ou uréia. Ciência Rural, v.35, p.284-289, 2005.

AZAM, F.; MALIK, K.A.; SAJJAD, M.I. Transformations in soil and availability to plants of ${ }^{15} \mathrm{~N}$ applied as inorganic fertilizer and legume residues. Plant and Soil, v.86, p.3-13, 1985.

AZAM, F.; MULVANEY, R.L.; SIMMONS, F.W. Effects of ammonium and nitrate on mineralization of nitrogen from legumes residues. Biology and Fertility of Soils, v.20, p.49-52, 1995.

BAIRD, C. Química ambiental. 2.ed. Porto Alegre: Bookman, 2002. 622p.

BARRIE, A.; PROSSER, S.J. Automated analysis of light-element stable isotopes by isotope ratio mass spectrometry. In: BOUTTON, T.W.; YAMASAKI, S.I. (Ed.). Mass spectrometry of soils. New York: Marcel Dekker, 1996. p.1-46.

BÜLL, L.T. Nutrição mineral do milho. In: BÜLL, L.T.; CANTARELLA, H. (Ed.). Cultura do milho: fatores que afetam a produtividade. Piracicaba: Potafos, 1993. 301p.

COELHO, A.M.; FRANÇA, G.E.; BAHIA FILHO, A.E.C.; GUEDES, G.A.A. Balanço de nitrogênio ${ }^{15} \mathrm{~N}$ em um Latossolo 
Vermelho-Escuro, sob vegetação de cerrado, cultivado com milho. Revista Brasileira de Ciência do Solo, v.15, p.187-193, 1991

CONAB. Milho: comparativo da área, produção e produtividade: safras 1976/1977 a 2007/2008. Disponível em: <http://www.conab. gov.br/conabweb/index.php?PAG=131>. Acesso em: 29 nov. 2008 .

DUETE, R.R.C.; MURAOKA T.; SILVA, E.C. da; TRIVELIN, P.C.O.; AMBROSANO, E.J. Manejo da adubação nitrogenada e utilização do nitrogênio $\left({ }^{15} \mathrm{~N}\right)$ pelo milho em Latossolo Vermelho. Revista Brasileira de Ciência do Solo, v.32, p.161-171, 2008.

EMBRAPA. Centro Nacional de Pesquisas de Solos. Sistema brasileiro de classificação de solos. Brasília: Embrapa Produção de Informação; Rio de Janeiro: Embrapa Solos, 1999. 412p.

FERNANDES, L.A.; VASCONCELOS, C.A.; FURTINI NETO, A.E.; ROSCOE, R.; GUEDES, G.A. de A. Preparo do solo e adubação nitrogenada na produção de grãos e matéria seca e acúmulo de nutrientes pelo milho. Pesquisa Agropecuária Brasileira, v.34, p.1691-1698, 1999.

FIGUEIREDO, C.C. de; RESCK, D.V.S.; GOMES, A.C.; URQUIAGA CABALLERO, S.S. Sistemas de manejo na absorção de nitrogênio pelo milho em um Latossolo Vermelho no Cerrado. Pesquisa Agropecuária Brasileira, v.40, p.279-287, 2005.

GAVA, G.J. de C.; TRIVELIN, P.C.O.; OLIVEIRA, M.W.; HEINRICHS, R.; SILVA, M. de A. Balanço do nitrogênio da uréia $\left({ }^{15} \mathrm{~N}\right)$ no sistema solo-planta na implantação da semeadura direta na cultura do milho. Bragantia, v.65, p.477-486, 2006.

GROVE, T.L.; RITCHEY, K.D.; NADERMAN, G.C. Nitrogen fertilization of maize on an Oxisol of the cerrado of Brazil. Agronomy Journal, v.72, p.261-265, 1980.

IAEA. International Atomic Energy Agency. Use of isotope and radiation methods in soil and water management and crop nutrition. Vienna: IAEA, 2001. 247p. (Training course series, 14).

INTERNATIONAL FERTILIZER INDUSTRY ASSOCIATION. Fertilizer use by crop. 5.ed. Disponível em: $<$ http://www.fertilizer. org/ifa/statistics.asp>. Acesso em: 19 jan. 2008.

JENKINSON, D.S.; FOX, R.H.; RAYNER, J.H. Interactions between fertilizer nitrogen and soil-nitrogen - the so-called "priming effect". Journal of Soil Science, v.36, p.425-444, 1985.

LARA CABEZAS, W.A.R.; ALVES, B.J.R.; URQUIAGA CABALLERO, S.S.; SANTANA, D.G. de. Influência da cultura antecessora e da adubação nitrogenada na produtividade de milho em sistema plantio direto e solo preparado. Ciência Rural, v.34, p.1005-1013, 2004.

LEE, R.B.; PURVES, J.V.; RATCLIFFER, R.G.; SAKER, L.R. Nitrogen assimilation and the control of ammonium and nitrate absorption by maize roots. Journal of Experimental Botany, v.43, p.1385-1396, 1992.

MARSCHNER, H. Mineral nutrition of higher plants. 2.ed. London: Academic Press, 1995. 889p.
MURAOKA, T.;AMBROSANO,E.J.;ZAPATA, F.;BORTOLETTO, N.; MARTINS, A.L.M.; TRIVELIN, P.C.O.; BOARETTO, A.E.; SCIVITTARO, W.B. Eficiencia de abonos verdes (crotalaria y mucuna) y urea, aplicados solos o juntamente, como fuentes de $\mathrm{N}$ para el cultivo de arroz. Terra, v.20, p.17-23, 2002.

NELSON, D.W.; SOMMERS, L.E. Total carbon, organic carbon and organic matter. In: PAGE, A.L.; MILLER, R.H.; KEENEY, D.R. (Ed.). Methods of soil analysis: chemical and microbiological properties. 2.ed. Madison: American Society of Agronomy: Soil Science Society of America, 1982. p.539-579.

RAIJ, B. van;ANDRADE, J.C. de; CANTARELLA, H.; QUAGGIO, J.A. (Ed.). Análise química para avaliação da fertilidade de solos tropicais. Campinas: Instituto Agronômico, 2001. 285p.

RAUN, W.R.; JOHNSON, G.V. Improving nitrogen use efficiency for cereal production. Agronomy Journal, v.91, p.357-363, 1999.

SAS INSTITUTE. The SAS-System for windows: release 6.11 . Cary: SAS Institute, 2001. 1 CD-ROM.

SCIVITTARO, W.B.; MURAOKA, T.; BOARETTO, A.E.; TRIVELIN, P.C.O. Utilização de nitrogênio de adubos verdes e mineral pelo milho. Revista Brasileira de Ciência do Solo, v.24, p.917-926, 2000.

SILVA, E.C. da; MURAOKA, T.; BUZETTI, S.; TRIVELIN, P.C.O. Manejo de nitrogênio no milho sob plantio direto com diferentes plantas de cobertura, em Latossolo Vermelho. Pesquisa Agropecuária Brasileira, v.41, p.477-486, 2006a.

SILVA, E.C. da; MURAOKA, T.; BUZETTI, S.; VELOSO, M.E. da C.; TRIVELIN, P.C.O. Absorção de nitrogênio nativo do solo pelo milho sob plantio direto em sucessão a plantas de cobertura. Revista Brasileira de Ciência do Solo, v.30, p.723-732, 2006 b.

SILVA, E.C. da; MURAOKA, T.; BUZETTI, S.; VELOSO, M.E. da C.; TRIVELIN, P.C.O. Aproveitamento do nitrogênio $\left({ }^{15} \mathrm{~N}\right)$ da crotalária e do milheto pelo milho sob plantio direto em Latossolo Vermelho de Cerrado. Ciência Rural, v.36, p.739-746, 2006c.

SILVA, E.C. da; MURAOKA, T.; ESPINAL, F.S.C.; TRIVELIN, P.C.O.; BUZETTI, S. Utilização do nitrogênio da palha de milho e de adubos verdes pela cultura do milho. Revista Brasileira de Ciência do Solo, v.32, p.2853-2861, 2008.

SOUSA, D.M.G. de; LOBATO, E. Adubação com nitrogênio. In: SOUSA, D.M.G. de; LOBATO, E. (Ed.). Cerrado: correção do solo e adubação. 2.ed. Planaltina: Embrapa Cerrados, 2004. p.129-144.

TORRES, J.L.R.; PEREIRA, M.G.; FABIAN, A.J. Produção de fitomassa por plantas de cobertura e mineralização de seus resíduos em plantio direto. Pesquisa Agropecuária Brasileira, v.3, p.421-428, 2008.

VILLAS BÔAS, R.L.; BOARETTO, A.E.; BÜLL, L.T.; GUERRINI, I.A. Parcelamento e largura da faixa de aplicação da uréia na recuperação do nitrogênio pela planta de milho. Scientia Agricola, v.56, p.1177-1184, 1999.

$\overline{\text { Recebido em } 4 \text { de setembro de } 2008 \text { e aprovado em } 30 \text { de janeiro de } 2009}$ 